\title{
ÔMEGA-3 NO TRATAMENTO PALIATIVO DO CÂNCER
}

\author{
Jaqueline Teles de Abreu Leite ${ }^{1}$ \\ Lívia Cabral Lobo ${ }^{2}$ \\ Leonardo Guimarães de Andrade ${ }^{3}$
}

RESUMO: Os ácidos graxos poli-insaturados ômega-3 encontrados no óleo de peixe e em peixes de alto teor lipídico, desempenham papel importante no tratamento paliativo do câncer. Possuem a capacidade de inibir a transcrição de genes próinflamatórios, inibindo a carcinogênese, retardam o crescimento de tumores, atuam na diferenciação celular, apoptose celular, melhoram a eficácia da quimioterapia e radioterapia, tendo em vista que auxiliam no aumento da resposta imunológica, na diminuição da toxicidade da quimioterapia e ainda diminuem as complicações associadas às feridas cirúrgicas, em virtude da diminuição da magnitude da resposta inflamatória típica do trauma. Além disso, diversos mecanismos de ação foram abordados com a finalidade de descrever a maneira pela qual o ácido graxo poliinsaturado ômega-3 pode alterar o processo de carcinogênese. $O$ estudo ora exposto, trata-se de revisão de literatura, a qual possui como principal objetivo apresentar os diversos benefícios da suplementação de ômega-3 no tratamento paliativo do câncer, trazendo como consequência a melhoria da qualidade de vida desses pacientes.

Palavra-chave: Câncer. Tratamento paliativo. Ômega-3. Suplementação.

ABSTRACT: Omega-3 polyunsaturated fatty acids found in fish oil and high-lipid fish play an important role in palliative cancer treatment. They have the ability to inhibit the transcription of pro-inflammatory genes, inhibit carcinogenesis, slow the growth of tumors, act on cell differentiation, cellular apoptosis, improve the efficacy of chemotherapy and radiotherapy, since they help in increasing the immune response, reducing the toxicity of chemotherapy and further reducing complications associated with surgical wounds, due to the decrease in the magnitude of the typical inflammatory response of trauma. In addition, several mechanisms of action have been addressed in order to describe the way in which omega-3 polyunsaturated fatty acid can alter the carcinogenesis process. The study, as presented, is a literature review, whose main objective is to present the various benefits of omega-3

\footnotetext{
'UNIG - Universidade Iguaçu, Curso de Graduação em Farmácia, Nova Iguaçu-RJ, Brasil.

${ }^{2}$ Msc. em Ciências de Tecnologia de Processos Químicos e Bioquímicos pela Universidade Federal do Rio de Janeiro (UFRJ). Professora assistente no Departamento de Farmácia da Universidade Iguaçu (UNIG).

${ }^{3}$ Msc. em Ciências do Meio Ambiente pela Universidade Veiga de Almeida (UVA). Integrante do corpo docente da Universidade Iguaçu (UNIG).
} 
supplementation in palliative cancer treatment, resulting in improving the quality of life of these patients.

Keyword: Cancer. Palliative treatment. Omega-3. Supplementation.

\section{INTRODUÇÃO}

O câncer é a patologia que mais causa morte no mundo. Cerca de um terço dos casos de câncer está relacionado com aspectos comportamentais e alimentares inadequados, como alto índice de massa corporal, baixo consumo de frutas e vegetais, ausência de atividade física e uso de álcool e tabaco (MARIANO, et al., 2019).

Atualmente o câncer, em algumas situações pode ser prevenido, porém se já diagnosticado ainda é possível submeter o indivíduo a um tratamento curativo. Além disso, não se pode descartar um diagnóstico letal, situação essa em que o paciente necessitará de cuidados paliativos, a fim de que se possa oferecer um maior conforto e qualidade de morte em determinados casos (MARIANO, et al., 2019).

Segundo o Instituto Nacional do Câncer (INCA), o tratamento paliativo refere-se aos cuidados de saúde ativos e integrais prestados a pessoa com doença grave, progressiva e que ameaça a continuidade de sua vida. São indicadas intervenções baseadas em cuidados multiprofissionais, composto por nutricionistas, psicólogos, assistente social, médicos, enfermeiros, fisioterapeutas, farmacêuticos, os quais irão exercer atividades diretamente ligadas às necessidades biopsicossociais.

Após o diagnóstico do câncer, o médico discutirá com o paciente sobre a melhor opção de tratamento, o qual dependerá do tipo de tumor, localização, estado geral de saúde do paciente, bem como os possíveis efeitos colaterais (ONCOGUIA, 202I).

Assim, o tratamento do câncer deve ser realizado de maneira individualizada, verificando-se as necessidades e possibilidades terapêuticas de cada paciente. $O$ paciente oncológico pode ser submetido a diferentes modalidades de tratamentos, como cirurgia, quimioterapia, radioterapia ou transplante de medula óssea, sendo 
possível em muitos casos, a combinação de mais de uma modalidade de tratamento (INCA, 2021).

Os ácidos graxos, até o início do século XX, eram observados tão somente como uma maneira eficiente de armazenar energia, possibilitando a ocorrência de síntese pelo organismo, a partir de proteínas e carboidratos. Diversas evidências apontam que uma dieta pobre em ácidos graxos está relacionada à vários problemas de saúde, que podem até levar ao óbito. Assim surgiu o conceito de ácidos graxos essenciais, ou seja, ácidos graxos imprescindíveis ao organismo, que não podem ser sintetizados e, portanto, devem ser fornecidos mediante a alimentação (SOUZA, 2014).

O ômega-3 trata-se de um ácido graxo poli-insaturado de cadeia longa, que consiste em um lipídio essencial composto por três ácidos graxos, que são: ALA (ácido alfa-linolênico), presente em vegetais, como a linhaça, precursor de EPA (ácido eicosapentaenoico) e DHA (ácido docosaexaenoico), encontrados em fontes animais, como óleo de peixe, entretanto, esses ácidos graxos não são sintetizados (MACHADO et al., 2019).

Estudos indicam que, enquanto compostos bioativos, os ácidos graxos ômega3 utilizados no tratamento oncológico, são vantajosos em comparação as drogas convencionais, uma vez que suas doses administradas para o tratamento são de baixa ou nenhuma toxicidade, e além disso, podem contribuir reduzindo a toxicidade da quimioterapia (CORREIA et al., 2020).

O ômega-3 possui diversos benefícios, ou seja, pode atuar inibindo a transcrição de genes pró-inflamatórios, inibindo a carcinogênese, retardando o crescimento de tumores, aumentando a eficácia da quimioterapia, radioterapia e melhorando a síntese muscular (LIMA, et al., 2014).

Além disso, o ômega-3 também mostra bons resultados nos pacientes oncológicos que precisaram passar por procedimento cirúrgico, uma vez que diminui a magnitude típica do trauma, bem como, em paciente com caquexia proveniente do 
câncer, uma vez que auxilia na terapia nutricional de maneira a manter e restabelecer a massa magra do paciente (CORREIA et al., 2020).

\section{OBJETIVOS}

\section{I OBJETIVO GERAL}

Apresentar os benefícios da suplementação de ômega 3 no tratamento paliativo em pacientes acometidos pelo câncer, visando a melhora da qualidade de vida desses pacientes.

\subsection{OBJETIVOS ESPECÍFICOS}

- Expor a fisiopatologia e o tratamento do câncer

- Descrever o mecanismo de ação do ômega 3 em pacientes oncológicos

- Relacionar os efeitos colaterais do tratamento oncológico com a suplementação do ômega 3

- Relacionar a suplementação de ômega 3 com pacientes oncológicos cirúrgicos

\section{METODOLOGIA}

O respectivo trabalho baseia-se em consulta a artigos científicos eletrônicos mediante consulta na base de dados do Google acadêmico, Scielo, (INCA) Instituto Nacional do Câncer. Além disso, utilizou-se as palavras chave: câncer, tratamento paliativo, ômega 3 e suplementação.

\section{JUSTIFICATIVA}

O tratamento do câncer inclui quimioterapia, radioterapia e até procedimentos cirúrgicos, que por serem agressivos, contribuem para evolução de grandes complicações e efeitos colaterais. Contudo, a ingestão de ômega 3 pode tratar 
de forma paliativa esses efeitos, tendo em vista a melhora da resposta imunológica e inflamatória, trazendo um impacto positivo da qualidade de vida dos pacientes.

\section{REVISÃO DE LITERATURA}

\section{I O CÂNCER}

Segundo o Instituto Nacional do Câncer (INCA), o termo câncer abrange mais de roo tipos distintos de doenças malignas em que ocorre um crescimento desordenado de células, as quais podem invadir tecidos e órgãos.

O câncer surge a partir de uma mutação genética. Essas alterações celulares podem ocorrer em genes especiais, denominados proto-oncogenes, que a princípio são inativos em células normais. Quando ativados, os proto-oncogenes tornam-se oncogenes, responsáveis por transformar as células normais em células cancerosas (INCA, 202I).

Figura r: Surgimento do Câncer

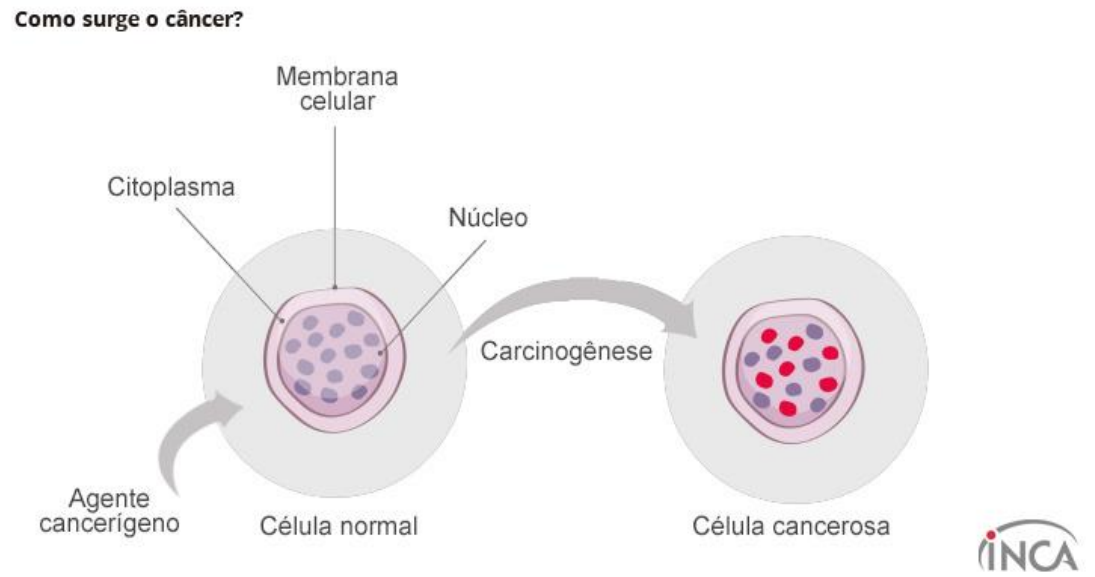

Fonte: INCA, 2021.

\subsection{ESTÁGIOS DO CÂNCER}


Segundo o Instituto Nacional do Câncer (INCA), a formação do câncer ocorre através de um processo denominado carcinogênese ou oncogênese. Esse processo é composto por três estágios:

Estágio de iniciação: Os genes sofrem alterações, em virtude da ação de agentes cancerígenos. Nesse estágio, as células apresentam-se geneticamente alteradas, entretanto ainda não é possível clinicamente a deteç̧ão de um tumor. As células tornam-se preparadas para a atuação de novos agentes que atuarão em um próximo estágio (INCA, 202I).

Estágio de promoção: A célula iniciada é transformada gradativamente em célula maligna, ou seja, as células geneticamente alteradas (iniciadas) sofrem o efeito dos agentes cancerígenos oncopromotores. Contudo, a suspensão do contato com esses agentes pode interromper o processo nesse estágio (INCA, 202I).

Estágio de progressão: Nesse estágio, o câncer já se encontra instalado. Assim, ocorre a multiplicação descontrolada e irreversível das células alteradas, que irão evoluir para as primeiras manifestações clinicas da doença (INCA, 202I).

Dessa forma, o câncer surge após uma alteração no DNA da célula, a qual recebe instruções erradas para suas atividades. Essas alterações celulares possuem uma origem multicausal por fatores endógenos e exógenos (CORREIA, et al., 2020).

Nota-se, portanto, que o câncer não possui uma única causa. Há inúmeras causas externas, as quais estão relacionadas ao meio ambiente. Assim, o ambiente em geral (água, terra e ar), ambiente de trabalho (indústrias químicas e afins), produtos de consumo (alimentos e medicamentos), bem como ações comportamentais (fumo e sedentarismo), são fatores de risco do câncer, denominados agentes cancerígenos ou carcinógenos, os quais contribuem para a alteração da estrutura genética das células (INCA, 202I).

Existem também as causas internas, as quais estão relacionadas a hormônios, condições imunológicas e mutações genéticas, que ao interagir de diversas formas podem dar origem ao câncer, tratando-se, portanto, da capacidade que o organismo tem de se defender dos fatores externos (INCA, 202I). 
Além disso, alguns fatores genéticos tornam determinadas pessoas mais suscetíveis a doença, bem como o envelhecimento natural do ser humano, trazendo alterações celulares e contribuindo para uma maior vulnerabilidade ao processo cancerígeno (INCA, 2021).

\subsection{O TRATAMENTO DO CÂNCER}

O tratamento oncológico dependerá de diversos fatores, isto é, tamanho do tumor, localização e extensão. Além disso, a saúde geral do paciente também deve ser levada em consideração, podendo-se aplicar diferentes tipos de modalidades terapêuticas, como quimioterapia, radioterapia, cirurgia e transplante de medula óssea. Contudo, a associação de duas ou mais modalidades terapêuticas podem ser realizadas em virtude da localização tumoral, obtendo-se um melhor resultado e maiores chances de cura (MAURÍCIO, 2014).

A quimioterapia consiste na modalidade de tratamento em que são utilizados medicamentos específicos para combater o câncer. Esses medicamentos atuam na destruição das células malignas, impossibilitando a formação de novo DNA, bloqueando funções essenciais das células ou induzindo a apoptose. Além disso, a quimioterapia pode ser realizada de maneira associada ao tratamento cirúrgico e a radioterapia (MAURÍCIO, 2014).

A radioterapia trata-se da utilização de radiação ionizante que tem por finalidade destruir ou inibir a proliferação do número de células do tumor, podendo ser associada a quimioterapia ou a outros recursos adjuvantes como tratamento paliativo. Na radioterapia ocorre uma aplicação de dose de radiação na zona que engloba o tumor (SOUZA, 2014).

A cirurgia oncológica consiste na remoção do tumor, bem como do tecido circundante, a qual pode ser utilizada como único meio de tratamento do câncer ou associada a quimioterapia e radioterapia. $O$ tratamento cirúrgico possui 
aplicabilidade com objetivo curativo ou paliativo, podendo ser indicado na maioria dos casos iniciais de tumores sólidos (SOUZA, 2014).

O transplante de medula óssea consiste em um tratamento proposto para algumas doenças que afetam as células sanguíneas, como as leucemias e os linfomas. Neste tipo de tratamento, ocorre a substituição de uma medula óssea doente por células normais de medula óssea, com a finalidade de reconstituição de uma medula saudável (INCA, 2021).

\section{4 ÁCIDOS GRAXOS POLI-INSATURADOS}

Os ácidos graxos poli-insaturados são obtidos através do consumo de alimentos ou ainda podem ser produzidos pelo organismo a partir dos ácidos linoleicos e alfa-linolênicos. Existem dois tipos de ácidos graxos essenciais, que são os ácidos graxos ômega-3 representado pelo ácido alfa-linolênico, e os ácidos graxos ômega-6, representados pelo ácido linoleico e araquidônico (SOUZA, 2014).

Figura 2: Estrutura química do ômega-3 e ômega-6
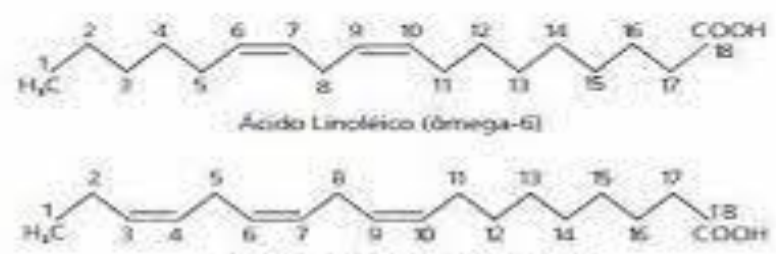

Acieb atfa- Bnolinices samoga-3)
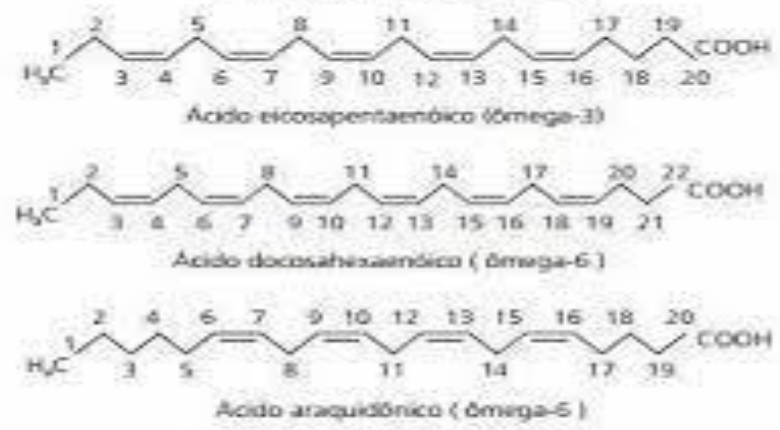

Fonte: Souza, 2014.

O ácido alfa-linolênico é um ácido poli-insaturado que se encontra presente nas plantas (linhaça, girassol, soja) e quando ingerido por animais, sofre desnaturação e alongamento de sua cadeia por enzimas que o converterão em EPA e 
DHA, obtidos principalmente de fontes animais, como óleo de peixe. Nota-se, portanto, que o ALA (ácido alfa-linolênico), trata-se de um precursor de EPA (ácido eicosapentaenoico) e DHA (ácido docosaexaenoico), os quais são considerados como ácidos graxos essenciais, uma vez que podem ser produzidos por vias endógenas mediante a ingesta do ácido alfa-linolênico (CORREIA et tal., 2020).

Podemos dizer, portanto, que uma das principais funções do ômega-3 e ômega-6 está relacionada a sua conversão enzimática em eicosanoides, uma vez possuir inúmeras atividades biológicas, como a modulação da resposta inflamatória, imunológica e além disso, desempenham papel de suma importância na agregação plaquetária, bem como no crescimento e diferenciação celular (CARMO \& CORREIA, 2009).

\subsection{MECANISMO DE AÇÃO DO ÔMEGA-3 NO CÂNCER}

O ômega-3 está relacionado a alguns mecanismos que atuam na modificação do processo da carcinogênese. Dessa forma, apontam-se alguns mecanismos de ação como:

\footnotetext{
Supressão da biossíntese dos eicosanoides que derivados do ácido araquidônico, resultando em modulação da resposta imunológica e inflamatória. às células tumorais; impacto na proliferação celular; na apoptose, na disseminação de metástases e na angiogênese; influência na atividade do fator de transcrição nuclear, na expressão gênica e nas vias de transdução de sinais, levando a mudanças no metabolismo celular, crescimento e diferenciação das células; alteração no metabolismo do estrogênio, gerando menor estímulo ao crescimento das células hormônio dependentes; aumento ou diminuição da produção de radicais livres; envolvimento em mecanismos diretamente relacionados à sensibilidade à insulina e à fluidez das membranas.(SOUZA, 2014, p.27).
}

A produção de eicosanoides inicia-se perante a liberação dos ácidos graxos poli-insaturados da membrana fosfolipídica pela ação de várias fosfolipases. Após essa liberação, esses ácidos graxos poli-insaturados servirão como substrato para cicloxigenases (COX), lipoxigenases (LOX) e citocromo $\mathrm{P}_{450}$ monoxigenase (CARMO \& CORREIA, 2009). 
A COX e a LOX atuam nos ácidos graxos de 20 carbonos onde produzirão moléculas de sinalização celular, como as prostaglandinas, tromboxanos e leucotrienos. As prostaglandinas $\left(\mathrm{PGE}_{2}\right)$ e os leucotrienos $\left(\mathrm{LTB}_{4}\right)$ são produzidas pelo ácido araquidônico (AA), as quais apresentam, na maior parte dos tecidos, ação pró-inflamatória e proliferativa, responsável pela indução da febre, aumento da permeabilidade vascular, causando dor e edema intensos. Entretanto, o EPA produz as $\mathrm{PGE}_{3}$, que por sua vez possuem efeito anti-inflamatório, fator que desfavorece o desenvolvimento e crescimento de células cancerosas (SOUZA, 2014).

As cicloxigenases ( $\mathrm{COX}$ ) possuem duas isoenzimas denominadas COX i e COX 2. A COX r é produzida pela maioria das células, enquanto que a $\operatorname{COX} 2$ é produzida como parte da resposta inflamatória. A presença do ômega-3 acarreta na inativação da $\operatorname{COX}$ 2, podendo trazer redução da resposta inflamatória com a modificação dos eicosanoides, passando a produzir os da série ímpar (antiinflamatória) e deixando de produzir os da série par (pró- inflamatória) (CARMO \& CORREIA, 2009).

O EPA corresponde ao substrato de preferência da (LOX), e por isso, se o ômega-3 estiver disponível, esses ácidos graxos serão utilizados como substratos tanto pela LOX quanto pela $\mathrm{COX}$, incorporando-se às membranas celulares, havendo uma diminuição do processo inflamatório. Dessa forma, os produtos da LOX e da COX provenientes do AA, estimulam a mitose, enquanto os que derivam do EPA diminuem o crescimento do tumor (SOUZA, 2014).

O fator de transcrição nuclear, ao ser ativado, promove o bloqueio da apoptose (morte celular). Nas células tumorais, este fator nuclear encontra-se normalmente alterado, resultando na resistência celular perante às drogas quimioterápicas e à radiação (CARMO \& CORREIA, 2009).

A expressão dos genes da família $\mathrm{Bcl}_{-2}$ e $\mathrm{COX} 2$ também tem o poder de bloquear a morte celular. Assim, os ácidos graxos ômega-3 possuem função reguladora do fator nuclear, regulando a expressão da $\operatorname{COX}$ 2, bem como a expressão 
dos genes da família Bcl-2, restaurando a apoptose fisiológica (CARMO \& CORREIA, 2009).

Alguns estudos indicam que tumores de vasta vascularização são mais invasivos e agressivos. Dessa forma, a angiogênese trata-se de uma estratégia para a inibição do crescimento tumoral. O ômega-3 possui uma capacidade inibitória em relação à angiogênese através de inúmeros mecanismos, como por exemplo, a alteração na produção de prostaglandinas e proteína cinase C (CARMO \& CORREIA, 2009).

Além disso, no câncer de mama dependente de estrogênio, a prostaglandina E2 ativa a $\mathrm{P}_{450}$ aromatase, resultando no aumento da produção de estrogênio. Assim, o ômega-3 poderia diminuir o crescimento do câncer nesse caso, tendo em vista a capacidade de reduzir a estimulação de estrogênio desses tumores (SOUZA, 2014).

\section{6 ÔMEGA-3 E OS EFEITOS COLATERIAS DO TRATAMENTO ONCOLÓGICO}

A carência nutricional acompanha a rotina do paciente acometido pelo câncer, sendo uma das maiores causas de morbidade e mortalidade na doença avançada. Assim, a perda de peso apresenta-se associada ao pior prognóstico da doença, resultando na piora da qualidade de vida. Vale ressaltar ainda, que o declínio do estado nutricional diminui a resposta do paciente ao tratamento, resultando em aumento da toxicidade e favorecendo o desenvolvimento de infecção (MAURÍCIO, 2014).

A caquexia do câncer consiste em uma síndrome multicausal caracterizada por uma inflamação sistêmica e uma importante diminuição da massa magra, a qual afeta cerca da metade de todos os pacientes oncológicos principalmente em estágio avançado, ocorrendo dentre várias manifestações clínicas, a anorexia e perda de peso. Os pacientes com caquexia normalmente são anoréxicos, tendo em vista a redução do apetite em razão do quadro inflamatório, bem como pelos efeitos colaterais do tratamento medicamentoso. Contudo, estudos recentes apresentam resultados 
benéficos com a utilização dos ácidos graxos poli-insaturados ômega-3 (CORREIA et tal., 2020).

Diante do exposto, estudo conduzido por Moses et al., apresentou resultados de melhora na qualidade de vida e aumento de peso em pacientes acometidos pelo câncer pancreático e caquexia debilitante, mediante a suplementação hipercalórica (61o kcal), hiperprotêica (32,2g de proteína), contendo 2,2g de EPA e o,96g de DHA. Já os pacientes que receberam a suplementação sem ômega-3, não apresentaram ganho de peso (CARMO \& CORREIA, 2009).

O paciente com câncer, em média de I a 2 semanas após ser submetido ao tratamento quimioterápico, apresenta uma grande probabilidade do aparecimento de xerostomia, isto é, boca seca. Dessa forma, em relação aos efeitos colaterais da doença e do tratamento quimioterápico, obteve-se resultado na melhora da xerostomia em pacientes submetidos a suplementação de ômega-3, sob a dosagem de 2,4g (4 cápsulas) em uma proporção de 2:I de DHA e EPA, num período de 3 a 6 meses, melhorando a qualidade de vida desses pacientes (OLIVEIRA \& MELO, 2020).

Ademais, o processo inflamatório consiste em um potencial fator que interfere e compromete a farmacocinética e a farmacodinâmica dos antineoplásicos. Verifica-se, portanto, que a suplementação de ômega-3 contribui para o controle da resposta inflamatória (LIMA, et al., 2014).

Dessa forma, demonstra-se em estudos, que a suplementação com ômega-3 pode atenuar a resposta inflamatória aguda, o que consequentemente previne o catabolismo, trazendo melhora na captação dos substratos energéticos e na resposta imune, contribuindo para um prolongamento da sobrevida de pacientes com câncer. Em contrapartida, outros estudos trazem evidências desfavoráveis com relação a suplementação do ômega-3, uma vez demonstrar que esses ácidos graxos poliinsaturados podem inibir a resposta imune medida por linfócitos $\mathrm{T}$, trazendo prejuízos principalmente aos pacientes imunossuprimidos (GARÓFOLO \& PETRILLI, 2006). 


\subsection{SUPLEMENTAÇÃO DO ÔMEGA-3 NA CIRURGIA ONCOLÓGICA}

O procedimento cirúrgico pode ser uma das alternativas aplicadas aos pacientes acometidos pelo câncer, o qual terá um propósito curativo ou paliativo. Dessa forma, possui finalidade curativa quando ocorre a remoção do tumor primário com margem de segurança e, caso seja necessário, a remoção dos linfonodos das cadeias de drenagem linfática no órgão do tumor primário. Já de forma paliativa, tem por objetivo diminuir a quantidade de células tumorais ou realizar o controle de sintomas que coloquem em risco a vida do paciente (MAURÍCIO, 2014).

A suplementação de ômega-3 em pacientes submetidos a cirurgia oncológica se mostra vantajosa, tendo em vista a possibilidade na diminuição da magnitude da resposta inflamatória típica do trauma (CARMO \& CORREIA, 2009).

De maneira conjunta com outros nutrientes, o EPA tem se mostrado benéfico ao sistema imune. Dessa forma, o Instituto Nacional do Câncer (INCA), tem indicado a suplementação com fórmulas imunomoduladoras no pré-operatório de cirurgias oncológicas de grande porte, o que resulta na diminuição das complicações, bem como do período de internação dos pacientes (SOUZA, 2014).

Frequentemente os pacientes com câncer apresentam complicações relacionadas a demora na cicatrização das feridas cirúrgicas. Assim, estudos demonstram que a imunonutrição (fórmula composta por arginina, ômega-z e RNA) no pré-operatório de pacientes que seriam submetidos a cirurgia em virtude de câncer gástrico, obtiveram efeitos benéficos, uma vez que apresentaram uma diminuição nas complicações associadas às feridas cirúrgicas, em comparação aos pacientes que não receberam a fórmula (CARMO \& FORTES, 2019).

\section{CONCLUSÃO}

Diante do exposto, podemos observar que a suplementação do ômega-3 traz benefícios importantes aos pacientes submetidos ao tratamento oncológico, uma vez que melhora a resposta inflamatória e imunológica, a síntese muscular, a caquexia associada ao câncer, xerostomia, melhorando também a cicatrização das feridas cirúrgicas, contribuindo para uma maior sobrevida do paciente. 
Verifica-se, também, que existem diferentes benefícios e formas de atuação do ômega-3, uma vez que diversos mecanismos contribuem de maneira simultânea para a supressão do crescimento do câncer.

Portanto, é possível observar a possibilidade de boas respostas com a suplementação de ômega-3 no tratamento paliativo do câncer. Contudo, a melhor abordagem no combate ao câncer ainda é a prevenção, tendo em vista que os resultados dependerão do estágio da doença e do tipo de câncer.

\section{REFERÊNCIAS BIBLIOGRÁFICAS}

CARMO, M.C.N.S.; CORREIA, M.I.T.D. A Importância dos Ácidos Graxos Ômega-3 no Câncer. Revista Brasileira de Cancerologia. n.55, v.3, p.279-287, 2009. Disponível em: https://rbc.inca..gov.br.

CARMO, S. G.; FORTES, R. C. Efeitos do uso de fórmulas imunomoduladoras em pacientes cirúrgicos portadores de câncer do trato gastrointestinal. Revista de Divulgação Científica Sena Aires. n.8, v.I, p. 96-III, 20I9. Disponível em: http://revistafacesa.senaaires.com.br

CORREIA, M.L.S.; VAZ, S. R.; PASSOS, X. S.; MAIA, Y.L.M. Ômega-3 como Composto Bioativo Adjuvante à Terapia Nutricional da Caquexia Oncológica. Revista Referência em Saúde da Faculdade Estácio de Sá de Goiás - RRS - FESGO. n. I, v. 03, p. I45-150, 2020. Disponível em: http://periodicos.estacio.br.

GARÓFOLO, A.; PETRILLI, A. S. Balanço entre ácidos graxos ômega-3 e 6 na resposta inflamatória em pacientes com câncer e caquexia. Revista de Nutrição. n. 19, v. 5, p. 6II- 62I, 2006. Disponível em: https:// www.scielo.br.

LIMA, B.S.; ALMEIDA, L.A.; FRANCO, E.P.D. Ação do ômega-3 no tratamento quimioterápico do câncer de mama. V Jornada de iniciação científica das faculdades integradas ASMEC. Minas Gerais, 2014. Disponível em: https://portal.unisepe.com.br.

INSTITUTO NACIONAL DO CÂNCER, INCA, Câncer, Brasil, 202I. Disponível em:<https:// www.inca.gov.br $>$. Acesso em: 5 de setembro de 2021.

MACHADO, G.; PUTON, B.F.; BERTOL, C. Nutracêuticos: aspectos legais e científicos. Revista Eletrônica de Farmácia. I6 (E), 2019. Disponível em: https://revistas.ufg.br.

MARIANO, Grace Kelly; MACEDO. Fernanda Larissa; FERRARI, Ariana. Alimentos Funcionais e Nutracêuticos no Câncer. In: XI ENCONTRO INTERNACIONAL DE PRODUÇÃO CIENTÍFICA, II, 2019, Maringá. Anais 
eletrônico. Maringá: Universidade Cesumar, 20r9. Disponível em: https://scholar.google.com.br.

MAURÍCIO, S.F. Impacto Nutricional no paciente oncológico. Revista Brasileira de Ciências da Vida. v. 2, 2014. Disponível em: https://scholar.google.com.br.

OLIVEIRA, A.C.R.; MELO, F. Efeito da suplementação de ômega-3 em pacientes com câncer. Repositório da PUC de Goiás. p. I-9, 2020. Disponível em: https://repositório.pucgoias.edu.br.

INSTITUTO ONCOGUIA, Oncoguia, Tratamentos do câncer, Brasil, 2018. Disponível em:<www.oncoguia.org.br/conteudo/tratamentos $>$. Acesso em: 03 de out. de 202I.

SOUZA, M. Avaliação do uso do ômega-3 em pacientes oncológicos: Uma revisão de literatura. Monografia (Graduação em Nutrição) - Centro de Ciências da Saúde Departamento de Nutrição da Universidade Federal da Paraíba. Paraíba, p. 1-43, 2014. Disponível em: https://scholar.google.com.br. 